Perspectivas em Ciência da Informação vem adotando nova denominação desde 1996, quando sucedeu a Revista da Escola de Biblioteconomia da UFMG, publicada desde 1972. Esta mudança de título visou adequar-se às novas tendências da área, alcançar um nível de qualidade no conteúdo das submissões e aumentar sua visibilidade nacional e internacionalmente.

Para alcançar tais objetivos, vem adotando o sistema de encaminhamento de cada artigo a três pareceristas: a um Membro do Conselho Editorial, e a dois Membros do Conselho Consultivo, sendo um professor ligado a Curso de Pós-Graduação, escolas ou departamentos da área, e o outro, um estrangeiro. Havendo sugestões, os pareceres são encaminhados aos autores, para apreciação e adequação do conteúdo. Concluída esta etapa, o texto revisto é encaminhado novamente aos pareceristas para decisão final sobre sua aceitação ou recusa.

Quando ocorrem sugestões, o processo demanda um prazo maior entre a data de sua submissão e a de sua aceitação. No entanto, ele tem se revelado positivo, no sentido de aprimorar o conteúdo das submissões.

Outra decisão adotada pelo Conselho Editorial foi a de para procurar ampliar a visibilidade de Perspectivas em Ciência da Informação, principalmente a nível internacional, através de sua disponibilização em meio magnético e a alteração de sua periodicidade, passando de semestral para quadrimestral, a partir do primeiro fascículo de 2006.

Simultaneamente, em junho do corrente, Perspectivas em Ciência da Informação foi aceita para integrar a Coleção SciELO Brasil http:// www.scielo.org e o Directory of Open Access Journals http:// www.doaj.org, o que constituiu motivo de satisfação entre os Membros do Conselho Editorial, da Escola de Ciência da Informação da UFMG e dos profissionais da área.

Este fascículo inclui oito artigos, uma revisão de literatura e resumos de teses e dissertações defendidas no Programa de Pós-Graduação em Ciência da Informação da ECI-UFMG.

\title{
Artigos
}

O primeiro artigo, Sistemas de recuperação de informações e mecanismos de busca na web: panorama atual e tendências, de Renato Rocha Souza, procura fornecer uma visão geral das características básicas dos sistemas de recuperação de informaações, enfatizando os mecanismos de busca na web. 
Serviços via Web em bibliotecas universitárias brasileiras, de Carlos Henrique Marcondes, Marília A. Mendonça e Suzana M. Carvalho, mostra os resultados de pesquisa que procurou identificar a existência de serviços oferecidos via Web em 209 bibliotecas universitárias de todas as regiões geográficas brasileiras, com maior número de cursos de pós-graduação. Os sites das bibliotecas foram visitados e avaliados, para se identificar os tipos de serviços oferecidos.

Elaboração e aplicação de instrumentos para avaliação da base de dados Scopus, de Rosa Mesquita, Sônia Brambilla, Rita do Carmo Laipelt, Maria de Fátima Maia, Samile Vanz e Sonia Elisa Caregnato, apresenta a metodologia e os critérios utilizados para a definição de um instrumento de avaliação de bases de dados, verificando a satisfação dos usuários quanto aos aspectos de conteúdo, funcionalidades do sistema e recuperação da informação. Relata a elaboração e aplicação deste instrumento para avaliação da base de dados Scopus por bibliotecários e usuários do Sistema de Bibliotecas da Universidade Federal do Rio Grande do Sul. Os resultados foram positivos em relação à satisfação dos usuários, quanto aos aspectos abordados.

Repositórios institucionais como ferramentas de gestão do conhecimento científico no ambiente acadêmico, de Fernando César Lima Leite e Sely Costa, mostra que é possível encontrar na literatura especializada estudos sobre gestão do conhecimento no âmbito de universidades e discute a adequação e a aplicabilidade dos repositórios institucionais como ferramenta de gestão do conhecimento científico.

Padronização da coleta de dados nas bibliotecas do SIBi/USP, de Dorotéa Maris Estela Fill, Diva Carraro Andrade, Eliana Rotolo, Gláucia Maria Saia Cristianini, Manuela Gea Cabrera Reis, Maria Helena Souza Ronchesel, Nelci Ramos Aguila, Roberto Barsotti, trata da coleta de dados estatísticos no SIBi/USP iniciada de forma padronizada e sistêmica a partir de 1987, utilizando como ferramenta o formulário denominado Relatório Individual por Bibliotecas e em 2002 foi criado um projeto específico para analisá-lo e aprimorá-lo. Apresenta as ações empreendidas: a revisão do Guia de Preenchimento do RIBi e a plataforma Web.

Digitalizando a memória de Salvador: nossos presente e passado têm futuro?, de Ricardo Andrade, Jussara Borges e Othon Jambeiro, aborda a migração de documentos para o formato digital, do acervo da Fundação Pierre Verger, mantendo-se intacta a informação. Conclui que só alcançará a plenitude dessa migração com a criação de redes e sistemas interoperáveis de informações arquivísticas.

Sociedade do conhecimento e ciência administrativa: reflexões iniciais sobre a gestão do conhecimento e suas implicações organizacionais, de Alexandre Shigunov Neto e Alexandre Andrade Teixeira, aborda o papel da gestão do conhecimento e suas implicações organizacionais na sociedade capitalista. Considera que o conhecimento é fator de produção distintivo na empresa e a necessidade de se obter melhor aproveitamento para efetivar os objetivos estratégicos das organizações.

Panorama da biblioteconomia e documentação na Argentina: análise dos anais da Associação de Bibliotecários Graduados da República Argentina ABGRA - 1990-200 I, de Gustavo Liberatore e Víctor Herrero Solana, delinea o estado da área naquele país, através da avaliação dos trabalhos incluídos nos anais da ABGRA e analisa qualitativa e quantitativamente os temas abordados, os métodos utilizados, as características da autoria e os padrões de citação. 


\section{Revisões de literatura}

Estudos de avaliação quantitativa e qualitativa de linguagens documentárias: uma síntese bibliográfica, de Vera Regina Casari Boccato e Mariângela Spotti Lopes Fujita discute as metodologias de avaliação propostas por pesquisadores nacionais e internacionais, e utilizadas por indexadores de instituiçõoes de ensino e/ou pesquisas atuantes em unidades de informação e/ou centros de documentação, e aquelas analisadas pelas opiniões dos próprios usuários da informação, registradas e disponibilizadas em sistemas de informações, focalizando as abordagens quantitativa, qualitativa e qualitativa/cognitiva.

Esperamos que os procedimentos adotados contribuam a partir dos fascículos para aumentar a qualidade dos trabalhos e a visibilidade de Perspectivas em Ciência da Informação. 